\title{
Quantifying degree of foot use impairment in hemiplegic gait using center-of-pressure trajectory vector difference integrals
}

\author{
TC Pataky ${ }^{*}$, H Tanaka, M Hashimoto \\ From 4th Congress of the International Foot and Ankle Biomechanics (i-FAB) Community \\ Busan, Korea. 8-11 April 2014
}

\section{Introduction}

Gait impairment manifestations can vary greatly amongst hemiplegic patients, so it is difficult to derive a single parameter to summarize impairment severity. In a separate study we found that the variance-normalized integrated difference amongst center-of-pressure (COP) trajectories was positively correlated with gait impairment severity. The purpose of this study was to test whether this COP trajectory difference parameter could also differentiate involved from uninvolved limbs in hemiplegia.

\section{Methods}

In-shoe COP trajectories were collected from (a) eight healthy students during treadmill walking, and (b) six hemiplegic patients during level-ground walking. Ten time-normalized COP trajectories per subject were analyzed. Each subject was compared to the mean Control trajectory by first computing the Hotelling's $T^{2}$ statistic at each point in time (Eqn.1), then integrating over stance phase (Eqn.2):

$$
\begin{aligned}
& T^{2}=n \Delta \bar{r} T W^{-1} \Delta \bar{r} \\
& \text { COP trajectory difference }=\int_{0}^{100 \%} T^{2}(t) d t
\end{aligned}
$$

Here $n=10$ is the number of footsteps, $\bar{r}$ is the instantaneous position difference between a subject's mean COP and the mean Control COP, and $W$ is its covariance (Figure 1a).
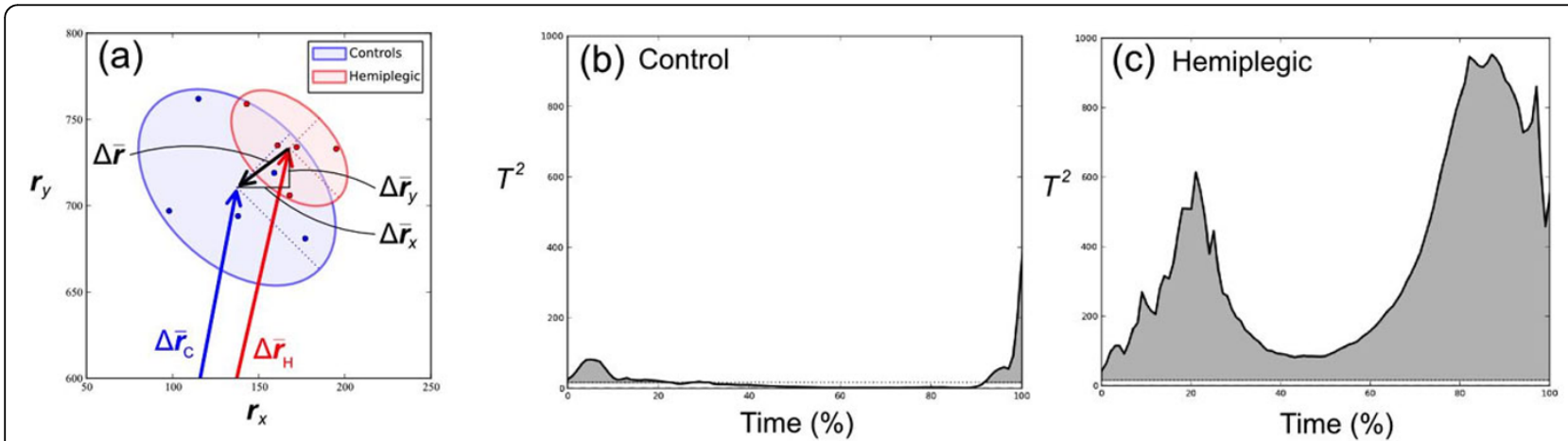

Figure 1 (a) Depiction of instantaneous vector difference with covariance ellipses. (b) Example Control $T^{2}$ trajectory depicting COP trajectory differences in time. (c) Example Hemiplegic $T^{2}$ trajectory.

\footnotetext{
* Correspondence: tpataky@shinshu-u.ac.jp

Department of Bioengineering, Shinshu University, Ueda, Nagano, Japan
} 


\section{Results}

Control subjects' COP trajectories were qualitatively more similar to the Control mean than were those of Hemiplegic subjects. Compared to Controls $(9.4 \pm 4.3)$ (Figure 1b), hemiplegic subjects exhibited greater $T^{2}$ integrals in both the involved $(123.7 \pm 117.3)(p=0.016)$ and uninvolved limbs $(30.2 \pm 14.4)(p=0.002)$ (Figure 1c). The $T^{2}$ integral also tended to be greater in the involved vs. uninvolved limbs within-subjects $(+252.2 \% \pm 200.0 \%)$ $(p=0.048)$.

\section{Discussion}

These results suggest that the $T^{2}$ integral appears to be useful metric for summarizing stance-phase foot use differences both within- and between-subjects. A broader range of clinical conditions are currently under investigation.

\section{Acknowledgements}

This work was supported by an ASTEP grant from the Japan Science and

Technology Agency.

Published: 8 April 2014

doi:10.1186/1757-1146-7-S1-A64

Cite this article as: Pataky et al:: Quantifying degree of foot use impairment in hemiplegic gait using center-of-pressure trajectory vector difference integrals. Journal of Foot and Ankle Research 2014 7(Suppl 1):A64.

Submit your next manuscript to BioMed Central and take full advantage of:

- Convenient online submission

- Thorough peer review

- No space constraints or color figure charges

- Immediate publication on acceptance

- Inclusion in PubMed, CAS, Scopus and Google Scholar

- Research which is freely available for redistribution

Submit your manuscript at www.biomedcentral.com/submit 